\title{
\#MeToo: the Role and Power of Bystanders (aka Us)
}

\author{
Rashi Aggarwal ${ }^{1}$ (D) Adam M. Brenner $^{2}$
}

Received: 6 December 2019 / Accepted: 12 December 2019/Published online: 17 December 2019

(C) Academic Psychiatry 2019

The medical profession is not immune to the phenomenon of sexual violence [1-5]. More than $50 \%$ of women faculty and students in medicine have reported being sexually harassed [1, 2]. We in medicine have been aware of gender discrimination and the differential when it comes to salaries, promotions, funding, and publications for some time now [6-9]. The \#MeToo movement [10], however, served as a catalyst for the outpouring of call-for-action commentaries [11-14] and the sharing of personal stories about sexual harassment in our workplaces [15-17]. It is clear that we have not done enough to address sexual harassment in our profession.

In the February 2019 issue of Academic Psychiatry, four articles examine different aspects of sexual harassment. McAdams [15] shares a personal account of being sexually harassed as a trainee and describes the trauma and growth from the lens of a psychiatrist who now works with patients who are survivors of abuse. Michael et al. [18] highlight both the high prevalence of inappropriate sexual behavior of patients toward trainees and the lack of training on how to handle such behavior. Coverdale et al. [19] discuss that sexual violence against women with psychiatric disorders has been missing from the conversations related to \#MeToo. Finally, Wainberg et al. [20] propose that a takeaway lesson from the \#MeToo movement is to teach about sexuality as a mental and physical health issue.

These articles shine a light on the fact that we in medicine might have been naïve in thinking that we are less susceptible to the problem, but if one looks at the underlying circumstances that favor sexual harassment, such as gender imbalances, uneven power structures, and promotional tracks, they are clearly present in medicine $[1,3,14]$. Attending physicians and senior leadership hold tremendous power over trainees and junior faculty. Many of the reports about sexual

Rashi Aggarwal

Rashi.Aggarwal@Rutgers.edu

1 Rutgers New Jersey Medical School, Newark, NJ, USA

2 University of Texas Southwestern Medical Center, Dallas, TX, USA harassment are from trainees (current or former), although sexual discrimination permeates medicine at all levels $[1,2$, $14,15]$. We must recognize that our professional environment is not that different from other professional environments and therefore is subject to similar issues. Corporate America is taking action to reduce sexual harassment in the workplace, and medicine can follow its lead and take similar actions.

In 1998, the Supreme Court put forth the Title VII Standards of Employer Liability for Supervisors' Conduct in Sexual Harassment Hostile Environment Cases [21], clarifying that to avoid liability, organizations must train their employees on their anti-harassment policies. Harassment and discrimination training programs have been rolled out across workplaces to different degrees. It is unclear how effective they are because while it is one thing to educate people about harassment, it is another to facilitate the reporting of harassment in a safe manner and yet another to actually follow through and address the concerns. Unfortunately, some workplace training programs are not only ineffective but may actually be detrimental $[1,11,14,22,23]$.

The \#NowWhat movement [24] is a follow up to \#MeToo and aims to bring into the open the discussion about how to address and prevent sexual harassment. Wide-scale, comprehensive reforms to reduce sexual harassment in medicine have been proposed $[1,11,13]$. The medical field is based on measurement and observability. If we bring the same rigor that we apply to medical research to this issue, we can implement programs that are actually effective at combating sexual harassment. We will be successful if we commit to eliminating harassment from our workplaces. It will not happen if, instead, we only commit to meeting legal standards to reduce workplace liability.

One prominent aspect of wide-scale organizational changes that has not received as much attention in medicine but has proven to be highly successful elsewhere is bystander intervention [24-29]. Members of academic departments should all be educated about the reporting requirements of their institution and any legal reporting obligations that may be specific to their local or state environment. These requirements can vary by institution, by jurisdiction, and over time. For 
example, Texas recently tightened its reporting requirements for all employees of state universities [30]. In this editorial, we highlight bystander intervention since it is the single most effective evidence-based intervention and can help change the culture and potentially have wide scale impact.

\section{Definitions}

First, here are some definitions of terms we are using in our editorial.

\section{Sexual Harassment}

Sexual harassment includes unwelcome sexual advances, requests for sexual favors, and other verbal or physical harassment of a sexual nature in the workplace or learning environment [31].

\section{Victim/Survivor}

A victim or survivor is the person at the receiving end of sexually harassing behavior. We use the term survivor in this editorial because for many women physicians the narrative of being a victim does not align with being a physician leader. The perspective in this issue [15] highlights this viewpoint.

\section{Perpetrator}

A perpetrator is the person who initiates sexually harassing behavior.

\section{Bystander}

A bystander is a person who is present when an event takes place but is not directly involved. Bystanders might be present when sexual assault or abuse occurs, or they could witness the circumstances leading up to these occurrences. For example, if a person makes a sexually suggestive joke about women in general, the person who makes the joke is the perpetrator of sexual harassment, the women present are the survivors, and everyone other than the perpetrator is a bystander.

\section{Why Do Bystanders Play an Important Role?}

There are a small number of perpetrators of sexual harassment, a relatively large number of survivors, and a larger number of bystanders. The above definitions drive home that last fact: anyone who witnesses the circumstances leading up to an unwelcome sexual advance or who is present when a negative comment about women as a group is made is a bystander. In any given sexual harassment situation, therefore, there are likely to be a large number of bystanders. Here is where the importance of the bystander comes in, both positively and negatively.

Perspective articles [15-17] about sexual harassment almost always refer to the presence of peers and colleagues (bystanders) during sexual harassment situations. It is very troubling to read of instances when bystanders invalidated the survivors [15]. It is one of the most potentially negative influences of bystanders: not only do they witness the occurrence, but also they may actually dismiss it, absolve the perpetrator, and put the blame on the survivor.

Bystander intervention training has proven effective on college campuses $[25,26]$ but has not been widely implemented in medicine. In the sections below, we discuss why bystanders may not intervene and what they can do to help. Once people understand how they can help and that helping does not necessarily require confronting or reporting the perpetrator, they may be more likely to intervene. Further, training and learning from examples might give us the confidence to start a dialog about the prevalence of sexual harassment in our workplaces and how to prevent it.

\section{Why Do Bystanders Not Intervene?}

Barriers to bystander intervention fall into three categories: (1) not recognizing that help is needed; (2) not knowing how to help; and (3) worrying that helping will result in negative consequences to self and the accused.

\section{Not Recognizing Help Is Needed}

The first barrier to bystander intervention, not recognizing help is needed, is essentially a reflection of the cultural climate. It includes not recognizing situations where harassment is taking place, not recognizing something inappropriate as inappropriate and a form of sexual harassment, and not feeling a responsibility to intervene [32-34]. This lack of identification of problematic behavior may be a reflection of personal beliefs, based on stereotypes about sexual violence, or due to lack of knowledge about the wide scale prevalence of sexual harassment in one's community [35, 36].

The bystander also may not understand the intent of the perpetrator and default to innocence. The bystander may not understand the impact of the perpetrated act on the survivor or not understand the survivor's underlying intent. For example, if a perpetrator makes a sexually suggestive comment, it may be viewed as a joke and also may not be clear to a bystander if there is an underlying relationship between the perpetrator and the survivor that makes the joke acceptable. The 2017 perspective by Jagsi [17] led to comments posted by women physicians who recounted personal experiences of sexual harassment. One describes how when the woman 
shared an incident with a male colleague, he laughed because he thought that the inappropriate behavior of the intoxicated colleague-perpetrator was funny.

To adequately address the barrier of not recognizing sexual harassment, one of the first steps, as proposed by Wainberg et al. in this issue [20], is to discuss and teach about sexuality, especially during psychiatry residency, as a health and a mental health issue. Making sexuality a topic that is openly discussed in the medical community can be a good starting place. Education should ideally also include the data and facts about sexual violence against women at large, against women with psychiatric disorders [19], and against trainees and colleagues. In addition, education should include open and honest dialog about changing norms [37].

One of the negative reactions to the \#MeToo movement has been concerned about what is acceptable, leading some to distance themselves from interactions with people of other genders as a protective measure $[12,37]$. The reaction may seem exaggerated, but it highlights the need for dialog about societal norms, power differentials, and the varying significance of situations to different people. Recognizing the mismatch in perceptions of a situation between a person with power and a person without power is essential to recognizing the difference between harassment and simple collegial interactions $[12,14,16,20]$. Here is a simple guideline: if you find yourself making an excuse for someone's behavior by saying, "They didn't mean anything by that" or "Oh, they are harmless" or "They were just joking," it may be time to stop and think if you are absolving a perpetrator and invalidating a survivor.

\section{Not Knowing How to Help}

The second barrier to bystander intervention is not knowing how to help or feeling helpless in a problematic situation [32, 34]. The first step to overcoming this barrier is to know the legal and institutional requirements for reporting sexual harassment, the prescribed steps to follow, and any possible penalties or liabilities from failing to report. A bystander who may recognize sexual harassment may not know how to intervene. Studies have found that a large number of people do not know what to do [38, 39] and want guidance about what to do [39]. Reports from survivors $[15,40]$ show that well-intentioned friends and colleagues might actually make unhelpful suggestions and comments that increase the difficulty of coping and recovery, whereas a helping hand by an observer may diffuse a situation and protect the survivor [17].

We believe that this feeling of helplessness might be one explanation for the lack of preparedness of psychiatry trainees to address inappropriate sexual behavior by patients as reported by Michael et al. in this issue [18]. They found a very high prevalence of sexual harassment from patients toward trainees. Echoing the findings from studies outside medicine,
$95 \%$ of the trainees wanted training on how to manage harassing behavior from patients. Sadly, only 5\% of the trainees in the sample consistently sought help after such encounters; most chose to not do so. The study found that $70 \%$ of the trainees had received no teaching either in a classroom setting or by supervisors on how to handle inappropriate behavior from patients. This finding is not surprising because most faculty have never received such training. However, as we will see in the subsequent section, simply talking about the problem is a powerful form of intervention.

\section{Worrying About Consequences}

The third barrier to bystander intervention is concern about the impact of intervention to self and the perpetrator. Even if bystanders recognize that an act is inappropriate, they may not be willing to take action such as reporting it to a third party. Reporting inappropriate behavior can carry with it the fear of retaliation, both overt and covert [11]. A large number of women choose not to report sexual harassment because of the fear of the consequences of reporting [1,15-17]. In an academic environment where people in power can both directly and indirectly (e.g., via negative comments) impact someone's career, the fear of retaliation holds for both survivors and bystanders. Unless the workplace leadership is serious about and committed to addressing sexual harassment in a way that protects the survivors and bystanders, reporting inappropriate behavior may come back to haunt the survivor or reporting bystander. Lack of clarity about the consequence of reporting inappropriate behavior can be a powerful deterrent too. Clear organizational policies of zero tolerance with a culture and climate of follow-through result in a significant increase in the willingness of survivors and bystanders to report sexual harassment [41].

We also may not want to label peers or colleagues as perpetrators because of the potential impact to them. If we witness a single inappropriate act, or even a few inappropriate acts, it may be easier to let the act(s) slide than to potentially incriminate someone we know or work with [42]. Statistics show, however, that the downstream impact of reporting sexual harassment is typically extremely negative for survivors and almost always negligible for perpetrators [1, 11, 16, 17]. Furthermore, studies have found rates of false reports of sexual assault between 2 and 10\% [43], whereas a 2016 survey found that only $23 \%$ of rapes and sexual assaults were actually reported to the police [44]. Thus, it is much, much more likely that someone will simply not report sexual harassment than make up false accusations.

A person coming forward with a complaint likely means that the person has been receiving such a significant amount of inappropriate behavior that the person is finally willing to risk very negative professional impact to report it. The least we can do as humans and colleagues is to take the person seriously. 
The sad reality is that we probably do not have to worry about our perpetrator-colleague; often, no action will be taken against the person, even if guilty, and the person will most likely escape unscathed $[1,16,17,45]$.

\section{What Can Bystanders Do?}

Bystander intervention training addresses the issues raised in the barriers to bystander intervention section above. Various trainings and models exist [46-48] and have similar principles. Along with any potential mandated reporting, bystanders can help in one or more of the following three ways: (1) diffuse the situation; (2) empathize with and support the survivor; and (3) directly address the perpetrator.

\section{Diffuse the Situation}

The first intervention is to distract the survivor or perpetrator or diffuse the situation. A bystander who observes that someone appears to be uncomfortable in a situation can step in to distract the perpetrator. This does not require an overt intervention, which can feel intimidating, but it can be as simple as changing the subject, interrupting the encounter, or distracting the survivor or perpetrator with a side conversation. Another option is to engage the person who appears harassed and help the person leave the situation [17]. Social events lend themselves more to this form of intervention.

A woman astronomer, having gone through the repeated experiences of being harassed at conferences, formed an organization called Astronomy Allies [49]. Members are potential bystanders who have volunteered to help. They follow the lead of the survivor, whether simply to be an empathic ear or a distracter or a diffuser of an inappropriate situation or an ally to help someone get out of an inappropriate situation. They are not active reporters or enforcers; they are there to listen and provide safety. Members wear an "Ally" badge, providing potential harassers a reminder that harassment is not welcome and assuring everyone else that they have an ally nearby.

Bystanders play an important role in everyday workplace encounters and situations, such as when someone makes demeaning or derogatory comments toward a specific gender or race. Addressing these micro-insults and micro-invalidations directly or indirectly can prevent an accumulation of insults to the survivors or intended groups. Addressing them might also prevent macro-assaults by changing what is acceptable in the culture $[37,50]$.

\section{Support the Survivor}

The second intervention is to empathize with and support the survivor. When a survivor talks about a situation or situations, simply be present and listen actively. If the situation is actively occurring, let the survivor tell you what is needed. If it is not an active, acute situation or when a survivor is willing to share, listening to the survivor and validating the concern is of paramount importance. Validating the survivor's experience does not mean judging the perpetrator. Being present for our colleagues the way we are trained to be present for our patients is an important gift that has been described by many survivors [15-17].

\section{Address the Perpetrator}

The third intervention is probably the most difficult. It is to directly confront the perpetrator during a sexual harassment encounter. Some of the strategies recommended by the National Sexual Violence Resource Center include being respectful but honestly labeling what is being seen [43]. For example, you can say, "What you just said made me uncomfortable" or "That did not sound appropriate to me." A bystander who does not belong to the target group being harassed, while possibly feeling uncomfortable, is still in a stronger and safer position to speak up than the targeted person.

\section{What Can You and I Do?}

It can be difficult to acknowledge that we live in a society where 1 in 5 women and 1 in 71 men are raped at some point in their lives [51], that the perpetrator is usually not a stranger [51] and that $8 \%$ of rapes occur at work [52]. As recently as 2018 [53], a survey found that $27 \%$ of women and $14 \%$ of men reported sexual harassment at work. It may be tempting to wonder in what workplaces such incidents occur ("they certainly cannot be any like ours"). In fact, academic workplaces have the second highest rate of sexual harassment, second only to the military [1]. One of us (RA) has spoken extensively about gender and leadership in medicine and psychiatry, and what brought these facts home for both of us was the perspective published in this issue that describes how sexual assault was experienced by one of our own - our colleaguewhile she was in training [15]. That is why each of these stories, while difficult to tell and difficult to read, is an essential part of the \#MeToo movement in medicine and psychiatry.

Much of the discussion about bystander intervention is generally applicable and not limited to the field of medicine. We bring the conversation to medicine and psychiatry because human health and behavior are our very job. The \#MeToo movement shone a light into our backyard and what we found is not flattering. We understand human beings; we understand sexuality, power dynamics, biases, emotions, and feelings. Yet, we have fallen short in protecting our own and those we serve. Yes, we need organizational changes and interventions, but we can also bring about change as individuals much more directly — by 
recognizing power dynamics, by realizing that in most inappropriate situations we may be bystanders and, therefore, we have the power to reduce and eliminate sexual harassment. We have to accept and be prepared for our roles as bystanders. The more we do, the easier it becomes. Studies have found that an increase in confidence in their skills leads to an increase in the likelihood of bystanders intervening [26, 46].

We can extend the individual responsibility and take it on in our professional societies. If at each meeting, conference, or social event, we follow the example set by Astronomy Allies [49], we will not have to wait for our individual workplace organizations to take action - we can bring about the change to the culture of medicine ourselves.

We hope that the articles in this issue of the journal inspire our readers to be open to the presence of sexual harassment in our field. And we hope that you choose to do something about it as individuals. Further, we hope that the articles inspire you to bring the hallmark of our profession - scientific inquiryto better understand sexual harassment in our field and find solutions to eliminate it.

\section{Compliance with ethical standards}

Disclosures On behalf of both authors, the corresponding author states that there are no conflicts of interest.

\section{References}

1. The National Academies of Sciences, Engineering, and Medicine. Consensus Study Report. Sexual harassment of women: climate, culture, and consequences in academic sciences, engineering, and medicine. Washington, DC: The National Academies Press; 2018. https://doi.org/10.17226/24994. Available at Accessed 11 December 2019

2. Fnais N, Soobiah C, Chen M, Lillie E, Perrier L, Tashkhandi M, et al. Harassment and discrimination in medical training: a systematic review and meta-analysis. Acad Med. 2014;89:817-27.

3. Frank E, Brogan D, Schiffman M. Prevalence and correlates of harassment among US women physicians. Arch Intern Med. 1998;158:352-8.

4. Carr PL, Ash AS, Friedman RH, et al. Faculty perceptions of gender discrimination and sexual harassment in academic medicine. Ann Intern Med. 2000;132:889-96.

5. Vargas EA, Brassel ST, Cortina LM, et al. \#MedToo: a large-scale examination of the incidence and impact of sexual harassment of physicians and other faculty at an academic medical center. J Women's Health. 2019. https://doi.org/10.1089/jwh.2019.7766.

6. Lo Sasso AT, Richards MR, Chou CF, Gerber SE. The $\$ 16,819$ pay gap for newly trained physicians: the unexplained trend of men earning more than women. Health Aff. 2011;30:193-201.

7. Jagsi R, Griffith KA, Stewart A, et al. Gender differences in salary in a recent cohort of early-career physician-researchers. Acad Med. 2013;88:1689-99.

8. Jagsi R, Griffith KA, Stewart A, Sambuco D, DeCastro R, Ubel PA. Gender differences in the salaries of physician researchers. JAMA. 2012;307(22):2410-7.
9. Jagsi R, Guancial EA, Worobey CC, Henault LE, Chang Y, Starr R, et al. The "gender gap" in authorship of academic medical literature-a 35-year perspective. N Engl J Med. 2006;355:281-7.

10. Me Too. https://metoomvmt.org/ Accessed 11.18.2019.

11. Binder R, Garcia P, Johnson B, Fuentes-Afflick E. Sexual harassment in medical schools: the challenge of covert retaliation as a barrier to reporting. Acad Med. 2018;93:1770-3.

12. Lee BH. \#Me Too movement; it is time that we all act and participate in transformation. Psychiatry Investig. 2018;15:433.

13. Choo EK, Byington CL, Johnson NL, Jagsi R. From \#MeToo to \#TimesUp in health care: can a culture of accountability end inequity and harassment? Lancet. 2019;393:499-502.

14. Launer J. Sexual harassment of women in medicine: a problem for men to address. Postgrad Med J. 2018;94:129-30.

15. McAdams CJ. Perspectives on sexual power, \#MeToo. Acad Psychiatry. 2019:1-3. https://doi.org/10.1007/s40596-019-011463.

16. Fox GS. We didn't see it coming, and you should have thought twice: sexual advances from our former teachers. Acad Psychiatry. 2018;42:555-8.

17. Jagsi R. Sexual harassment in medicine-\#MeToo. N Engl J Med. 2018;378:209-11.

18. Michael S, Chen X, Raymond E, Capasso R. Prevalence of and preparedness to address inappropriate sexual behavior from patients during psychiatry training: a pilot study. Acad Psychiatry. 2019:15. https://doi.org/10.1007/s40596-019-01094-y.

19. Coverdale J, Roberts L, Balon R, et al. \#MeToo and female patients with major mental disorders: what should academic psychiatry do? Acad Psychiatry. 2019. https://doi.org/10.1007/s40596-019-011365.

20. Wainberg ML, McKinnon K, Cournos F. Learning from \#MeToo: a call to action in the training of psychiatric faculty and residents to discuss sexuality as a health and mental health issue. Acad Psychiatry. 2019:1-5. https://doi.org/10.1007/s40596-019-010519.

21. US Equal Employment Opportunity Commission. Digest of EEO Law, Volume XI, No. 6. Available at https://www.eeoc.gov/federal/ digest/xi-6-2.cfm Accessed 11.22.19

22. Grant R. Why do employers keep providing the same ineffective sexual harassment training? Available at https://qz.com/work/ 1647165/why-is-sexual-harassment-training-so-ineffective/ Accessed 11.22.19

23. Bezrukova K, Spell CS, Perry JL, Jehn KA. A meta-analytical integration of over 40 years of research on diversity training evaluation. Psychol Bull. 2016;142:1227-74.

24. Durana A, Lenhart A, Miller R, et al. \#NowWhat: the sexual harassment solutions toolkit. https://www.newamerica.org/better-lifelab/reports/nowwhat-sexual-harassment-solutions-toolkit/ Acessed 11.19. 19.

25. Potter SJ, Moynihan MM. Bringing in the bystander in-person prevention program to a U.S. military installation: results from a pilot study. Mil Med. 2011;176:870-5.

26. Cares AC, Banyard VL, Moynihan MM, Williams LM, Potter SJ, Stapleton JG. Changing attitudes about being a bystander to violence: translating an in-person sexual violence prevention program to a new campus. Violence Against Women. 2015;21:165-87.

27. Peterson K, Sharps P, Banyard V, Powers RA, Kaukinen C, Gross $\mathrm{D}$, et al. An evaluation of two dating violence prevention programs on a college campus. J Interpers Violence. 2018;33:3630-55.

28. Miller CC. Sexual harassment training doesn't work. But some things do. New York Times, 2017. Available at https://www. nytimes.com/2017/12/11/upshot/sexual-harassment-workplaceprevention-effective.html. Accessed 11.22.19.

29. Coker AL, Cook-Craig PG, Williams CM, Fisher BS, Clear ER, Garcia LS, et al. Evaluation of green dot: an active bystander 
intervention to reduce sexual violence on college campuses. Violence Against Women. 2011;17:777-96.

30. Korte L. New laws aim to boost Title IX reporting at Texas universities. Statesman, September 1, 2019. Available from https://www. statesman.com/news/20190901/new-laws-aim-to-boost-title-ixreporting-at-texas-universities. Accessed 12.4.19.

31. U.S. Equal Employment Opportunity Commission. Facts about sexual harassment. Available from https://www.eeoc.gov/eeoc/ publications/fs-sex.cfm. Accessed 11.28.19.

32. Burn SM. A situational model of sexual assault prevention through bystander intervention. Sex Roles. 2009;60:779-92.

33. Banyard VL, Moynihan MM. Variation in bystander behavior related to sexual and intimate partner violence prevention: correlates in a sample of college students. Psychol Violence. 2011;1:287-301.

34. Bennett S, Banyard VL, Garnhart L. To act or not to act, that is the question? Barriers and facilitators of bystander intervention. J Interpers Violence. 2014;29:476-96.

35. Thomas M. New data reveals high awareness among U.S. adults on what constitutes sexual assault. National Sexual Violence Resource Center, 2017. Available from https://www.nsvrc.org/blogs/pressreleases/new-data-reveals-high-awareness-among-us-adults-whatconstitutes-sexual Accessed 11.27.19.

36. VicHealth. Australians' attitudes to violence against women. Available from https://www.vichealth.vic.gov.au/media-andresources/publications/2013-national-community-attitudestowards-violence-against-women-survey Accessed 11.27.19.

37. Drezner DW. \#MeToo and the trouble with new norms. Washington Post, 2018. Available at: https:/www.washingtonpost.com/news/ posteverything/wp/2018/02/14/metoo-and-the-trouble-with-norms Accessed 11.23.19.

38. Knowledge Networks. College dating violence and abuse poll, 2011. Available from http://www.loveisrespect.org/pdf/College Dating_And_Abuse_Final_Study.pdf Accessed 11.28.19.

39. Office on violence against women. Bystander-focused prevention of sexual violence. Available from https://www.justice.gov/ archives/ovw/page/file/905957/download Accessed 11.29.19.

40. Sylaska KM, Edwards KM. Disclosure of intimate partner violence to informal social support network members: a review of the literature. Trauma Violence Abuse. 2014;15:3-21.

41. Jacobson RK, Eaton AA. How organizational policies influence bystander likelihood of reporting moderate and severe sexual harassment at work. Empl Responsib Rights J. 2018;30:37-62.

42. Hagi S. Cancel culture is not real-at least not in the way people think. Time, 2019. Available from https://time.com/5735403/ cancel-culture-is-not-real/ Accessed 11.29.19.
43. National Sexual Violence Resource Center. bystander intervention tips and strategies. 2018. Available from https://www.nsvrc.org/ sites/default/files/2018-02/publications_nsvrc tip-sheet bystanderintervention-tips-and-strategies_1.pdf. Accessed 11.27.19.

44. Morgan RE, Kena G. Criminal Victimization, 2016: Revised. Bureau of Justice Statistics, 2018. Available from https://www. bjs.gov/content/pub/pdf/cv16.pdf. Accessed 12.3.19.

45. Firth $\mathrm{S}$. When mentor becomes aggressor: why victims stay silent. MedPage Today, 2019. Available from https://www.medpagetoday. com/special-reports/metoo/78279. Accessed 11.28.19.

46. Banyard MM, Moynihan MM, Plante EG. Sexual violence prevention through bystander education: an experimental evaluation. J Commun Psychol. 2007;35:463-81.

47. Rape, Abuse and Incest National Network. Steps You Can Take to Prevent Sexual Assault. Available from https://rainn.org/articles/ steps-you-can-take-prevent-sexual-assault?_ga=2.74340114. 1856075668.1574802652-909593517.1574802652 Accessed 11. 28.19 .

48. The College of New Jersey Anti-Violence Initiatives. The 3 D's of Bystander Intervention. Available from https://oavi.tcnj.edu/greendot/the-3-ds-of-bystander-intervention/ Accessed 11.29.19.

49. Astronomy Allies. What are the Astronomy Allies? Available from http://www.astronomyallies.com/Astronomy_Allies/Welcome. html Accessed 11.28.19.

50. McClure E. Theorizing a spectrum of aggression: microaggressions, creepiness, and sexual assault. Pluralist. 2019;14:91-101.

51. Black MC, Basile KC, Breiding MJ, et al. The National Intimate Partner and Sexual Violence Survey (NISVS): 2010 summary report. Atlanta, GA: National Center for Injury Prevention and Control, Centers for Disease Control and Prevention. Available from http://www.cdc.gov/ViolencePrevention/pdf/NISVS Report2010-a.pdf Accessed 11.30.19.

52. Duhart D. Violence in the Workplace, 1993-99. Bureau of Justice Statistics. 2001. Available from https://www.bjs.gov/content/pub/ pdf/vw99.pdf Accessed 11.30.19.

53. Edison Research. Sexual harassment in the workplace: A marketplace survey. 2018. Available from http://www.edisonresearch. com/wp-content/uploads/2018/06/Sexual-Harassment-in-theWorkplace-metoo-Women-Men-and-the-Gig-Economy-6.20.18-1. pdf Accessed 11.30.19.

Publisher's Note Springer Nature remains neutral with regard to jurisdictional claims in published maps and institutional affiliations. 